\title{
Carbonation Behavior of Powdered Cement-Based Materials Under Different Relative Humidities and $\mathrm{CO}_{2}$ Concentrations
}

\author{
Kiyofumi Nakada ${ }^{1}$, Katsuhito Komiya ${ }^{2}$, Hikaru Fumino ${ }^{2}$, Yuhei Nishio ${ }^{2}$, Manabu \\ Kanematsu $^{2}$ and Takafumi Noguchi ${ }^{3}$ \\ ${ }^{1}$ Department of Building Materials and Components, Building Research Institute, 1 Tachihara, \\ Tsukuba-shi, Ibaraki-ken 305-0802, Japan,nakada@kenken.go.jp \\ ${ }^{2}$ Department of Architecture, Graduate School of Science and Technology, Tokyo University of \\ Science, 2641 Yamazaki, Noda-shi, Chiba-ken 278-8510, Japan, manabu@rs.tus.ac.jp \\ ${ }^{3}$ Department of Architecture, Graduate School of Engineering, The University of Tokyo, 7-3-1 \\ Hongo, Bunkyo-ku, Tokyo, Japan, noguchi@bme.arch.t.u-tokyo.ac.jp
}

\begin{abstract}
The aim of the current study is to investigate the carbonation behavior of cement hydrates at different environments. Hardened cement pastes are prepared using OPC and BFS and crushed into $\sim 90 \mu \mathrm{m}$ powder. The powder samples are carbonated at 5/20\% CO 2 and at 60/85\%RH. TGA, XRD and phenolphthalein tests are conducted before and after carbonation. The results show that $C H$ remain uncarbonated even after $\mathrm{CO}_{2}$ uptake apparently ended and that the amount of the residual $\mathrm{CH}$ affects the results of phenolphthalein test. External humidity strongly affects the carbonation behavior of both $\mathrm{CH}$ and other hydrates. The degree of $\mathrm{CH}$ carbonation is greater at higher humidity, while the degree of other hydrates carbonation is greater at lower humidity. This conflicting effect can occur at surface of bulk concretes and changes in its properties (coarsening of pore structure and cracking) can be caused without apparent carbonation detected by phenol phthalein test. The effect of relative humidity on CSH carbonation should be taken into consideration when estimating long-term performance of carbonated concretes.
\end{abstract}

Keywords: Carbonation, OPC, BFS, Relative Humidity, Phenolphthalein Test.

\section{Introduction}

Carbonation of concrete leads to significant changes in its chemical and physical properties. During the process, gaseous $\mathrm{CO}_{2}$ diffuses through pore network of concrete and react with cement hydrates. When Portlandite $(\mathrm{CH})$ is carbonated and consumed, $\mathrm{pH}$ value of pore water decreases, which causes depassivation of steel bars embedded in RC structures. $\mathrm{CH}$ carbonation also contributes to reduction in concrete porosity because precipitated calcium carbonate (Ĉ̂) clogs up the pore space. The clogging of porosity results in a decrease of diffusion path, which improves weight transport resistance in general (Houst et al., 1994). In terms of porosity change, it has been reported that carbonation of calcium silicate hydrate $(\mathrm{CSH})$ has greater impact than $\mathrm{CH}$ carbonation (Morandeau et al., 2014). CSH carbonation also alters pore size distribution of cement pastes, which can cause coarsening of pore structure (Auroy et al., 2014). Furthermore, it has been known that CSH carbonation is responsible for carbonation shrinkage and subsequent cracking (Chen et al., 2006).

Summarizing the above, carbonation reaction of cement hydrates governs the property changes of carbonated concrete. Better understanding on both the reaction behavior and the impacts can help us to estimate the long-term performance of carbonated concretes. Up to the 
present, the impacts of cement hydrate carbonation has been widely investigated (Borges et al., 2010; Auroy et al., 2014), and the changes in physical properties can be related to the degree of carbonation (Morandeau et al., 2014). On the other hand, data on carbonation behavior of cement hydrates are lacking.

As has been already known, carbonation behavior of cement hydrates is strongly affected by external environment (Castellote et al., 2009; Galan et al., 2013). Thus, the aim of the current study is to investigate the carbonation behavior of cement pastes at different humidity and $\mathrm{CO}_{2}$ concentration. Also, cement hydrates inside bulk concretes are carbonated under changing environments (humidity and $\mathrm{CO}_{2}$ concentration), because concrete carbonation basically occurs during drying process. In order to estimate the carbonation degree at any environment, it is desirable to remove the bulk effect and to obtain direct relationship between the carbonation degree and external environments. Considering the above, powdered samples (hardened cement pastes) are employed in this study.

\section{Materials and Experiments}

3 types of cement pastes were prepared. 2 of them were made with OPC (LOI: $0.97 \%, \mathrm{SiO}_{2}$ : $\left.21.41 \%, \mathrm{Al}_{2} \mathrm{O}_{3}: 4.84 \%, \mathrm{Fe}_{2} \mathrm{O}_{3}: 3.20 \%, \mathrm{CaO}: 65.01 \%, \mathrm{MgO}: 1.08 \%, \mathrm{SO}_{3}: 2.02 \%\right)$ and their water to cement ratio were 0.45 and 0.60 (N45 and N60). The other was made with OPC and BFS (50:50) and its water to cement ratio was 0.60 (BB60). The pastes were cast into prismatic molds $(40 \times 40 \times 160 \mathrm{~mm})$ and demolded after 24 hours. They were cured until 91 days under

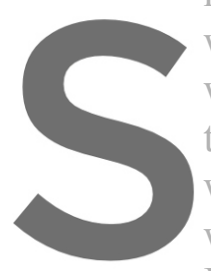
water, and then crushed into were sieved with $90 \mu \mathrm{m}$ mesh. temperature and humid were carbonated at 4 different was $20^{\circ} \mathrm{C}, \mathrm{CO}_{2}$ concentr
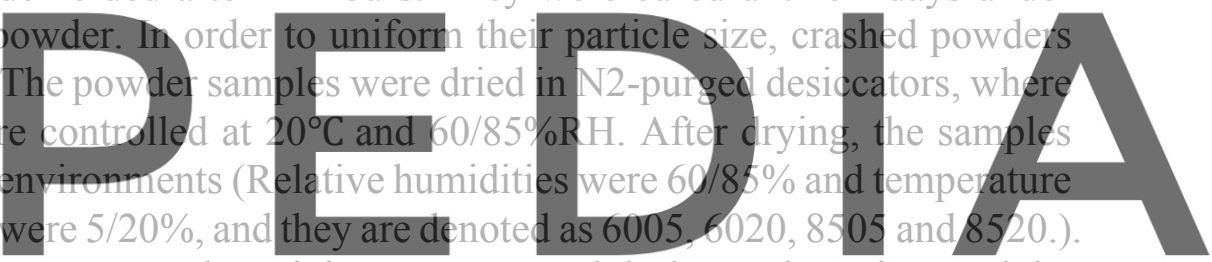

In order to monitor $\mathrm{CO}_{2}$ uptake rate, sample weight was measured during carbonation, and the

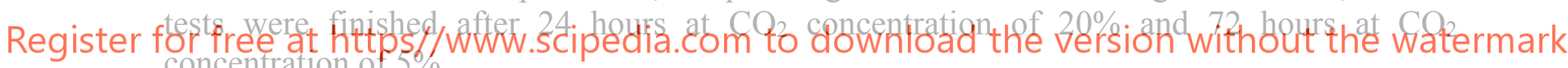
concentration of $5 \%$.

After accelerated carbonation, TGA tests were performed on carbonated and non-carbonated samples. Measurement temperature ranged from $105^{\circ} \mathrm{C}$ to $1050^{\circ} \mathrm{C}$ at the heating rate of $10^{\circ} \mathrm{C} / \mathrm{min}$. The amount of $\mathrm{CH}$ and $\mathrm{CC}$ were calculated from $\mathrm{TG}$ curves and their decomposition was detected from inflection point of $\Delta \mathrm{TG}$ curves around $400^{\circ} \mathrm{C}$ to $550^{\circ} \mathrm{C}$ and $550^{\circ} \mathrm{C}$ to $800^{\circ} \mathrm{C}$. Before the tests the samples were soaked in acetone for 48 hours and dried in vacuum desiccator. XRD tests were also performed on the same samples. Patterns were obtained from $2 \theta$ of $5^{\circ}$ to $65^{\circ}$. In addition to TGA and XRD tests, phenolphthalein tests were carried out so as to compare apparent carbonation and the degree of carbonation. The powders are packed into sample holder $(10 \times 10 \times 0.2 \mathrm{~mm})$, and phenolphthalein solution was dropped onto them. Sample color was measured by means of color difference meter before and after phenolphthalein was dropped.

\section{Results}

\subsection{Weight Change and $\mathrm{CO}_{2}$ Uptake}

Figure 1. shows the results of monitoring of the sample weight during carbonation at $5 \% \mathrm{CO}_{2}$ concentration. Sample weight shapely increased in first 8 hours, but the change slowed down 
quickly and was completed within 24 hours in most samples. The weight increase is mainly due to $\mathrm{CO}_{2}$ uptake and evaporation of water generated through carbonation reaction. In the case of OPC system, larger amount of $\mathrm{CO}_{2}$ was absorbed when water to cement ratio and external humidity is higher. On the other hand, little difference can be found in OPC-BFS system, although gentle weight increase continued after 24-hour carbonation at $60 \% \mathrm{RH}$. In Figure 2, influence of $\mathrm{CO}_{2}$ concentration on the weight change is compared. As expected, increase in sample weight was higher when $\mathrm{CO}_{2}$ concentration is higher. and the influence is more obvious in higher relative humidity.
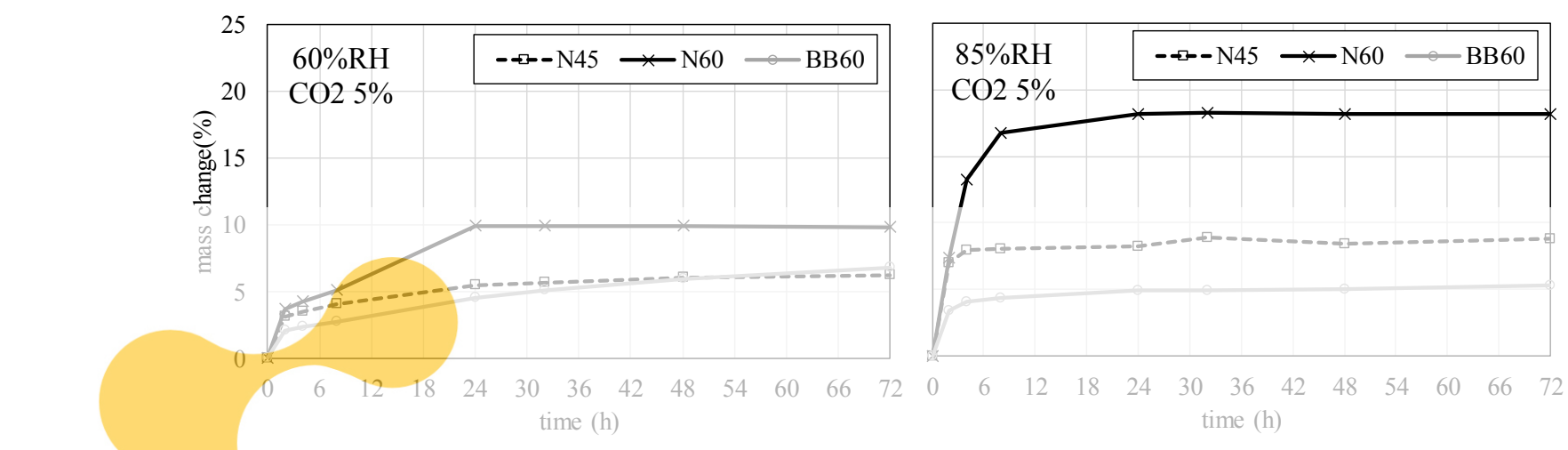

Figure 1. Sample weight monitored during carbonation $\left(5 \% \mathrm{CO}_{2}\right)$.
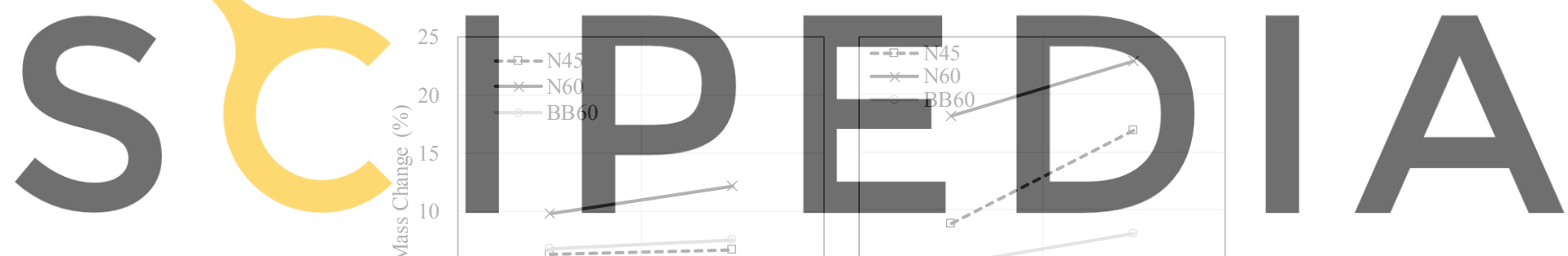

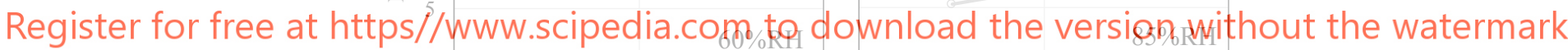
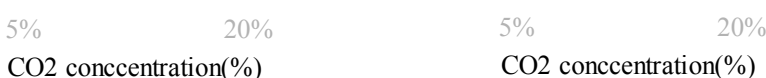

Figure 2. Weight change after carbonation. Carbonation time was 24 hours for $20 \% \mathrm{CO}_{2}$ and 72 hours for $5 \%$ $\mathrm{CO}_{2}$.

\subsection{Carbonation Behavior of Cement Hydrates}

Figure 3. shows the results of TGA tests before and after carbonation. In some cases, especially in lower relative humidity, $\mathrm{CH}$ dose not reach full carbonation even after $\mathrm{CO}_{2}$ uptake apparently stopped (Figure 1.). It has been pointed out that degree of $\mathrm{CH}$ carbonation is strongly affected by external humidity and that larger amount of $\mathrm{CH}$ is carbonated in more humid environment (López-Arce et al., 2011; Galan et al., 2015). In Figure 3, the results of 5\% $\mathrm{CO}_{2}$ concentration are coincide with the reported behavior of $\mathrm{CH}$ carbonation, although little difference can be found in the residual $\mathrm{CH}$ of $20 \% \mathrm{CO}_{2}$ concentration. 
In addition to the TGA results, the amount of $\mathrm{C} \hat{\mathrm{C}}$ generated from $\mathrm{CH}$ carbonation $\left(n_{\mathrm{C} \hat{\mathrm{C}}}^{\mathrm{CH}}\right)$ and other hydrates carbonation $\left(n_{\mathrm{C} \hat{C}}^{\text {others }}\right)$ is calculated using the following equations.

$$
\begin{gathered}
n_{\mathrm{C} \hat{\mathrm{C}}}^{\mathrm{CH}}=n_{\mathrm{CH}, \mathrm{nc}}-n_{\mathrm{CH}, \mathrm{c}} \\
n_{\mathrm{C} \hat{\mathrm{C}}}^{\text {others }}=n_{\mathrm{C} \hat{\mathrm{C}, \mathrm{c}}}-n_{\mathrm{C} \hat{\mathrm{C}, \mathrm{nc}}}-n_{\mathrm{C} \hat{\mathrm{C}}}^{\mathrm{CH}}
\end{gathered}
$$

Where $n_{\mathrm{CH}, \mathrm{nc}}$ and $n_{\mathrm{CH}, \mathrm{c}}$ are the amount of $\mathrm{CH}$ contained in non-carbonated and carbonated

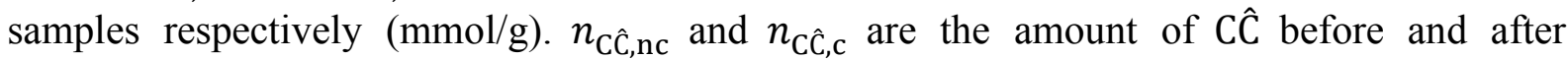
carbonation ( $\mathrm{mmol} / \mathrm{g})$.

The calculation results (grey and yellow lines in Figure 3.) illustrate that relative humidity also has impact on other hydrates carbonation. In most cases, larger amount of C $\hat{C}$ is generated from other hydrates at $60 \% \mathrm{RH}$ than at $85 \% \mathrm{RH}$, and the amount of C $\hat{\mathrm{C}}$ from other hydrates exceeds that from $\mathrm{CH}$ carbonation at $60 \% \mathrm{RH}$. This general tendency is similar to carbonation behavior of synthesized CSH reported elsewhere (Kim et al. 1995), where it has been pointed out that $\mathrm{CSH}$ carbonation continues longer and greater amount of $\mathrm{CO}_{2}$ is absorbed at $60 \% \mathrm{RH}$ than at $80 \%$ RH. In summary, higher humidity promotes $\mathrm{CH}$ carbonation and larger amount of $\mathrm{CH}$ is consumed. On the other hand, lower relative humidity contributes to other hydrate carbonation and larger amount of $\mathrm{CH}$ remain uncarbonated.
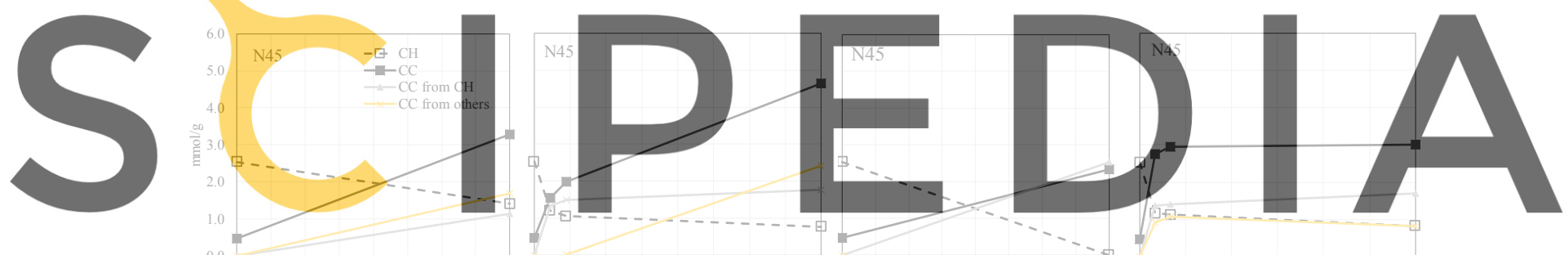

Register for ${ }^{6}$ free at https//www. seipedia.com to download the version without the watermark
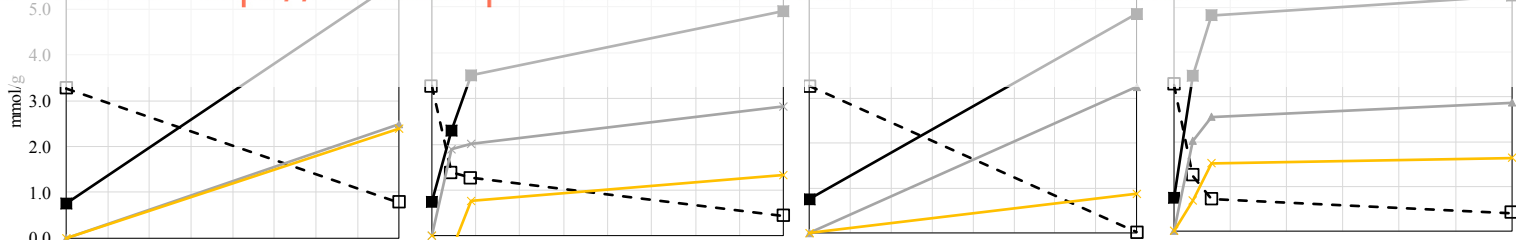

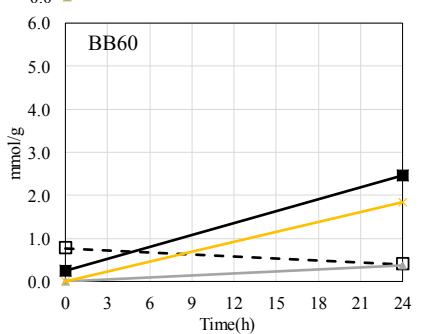

6005

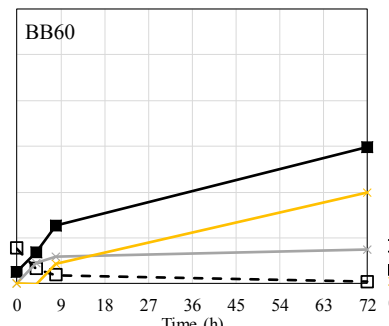

6020

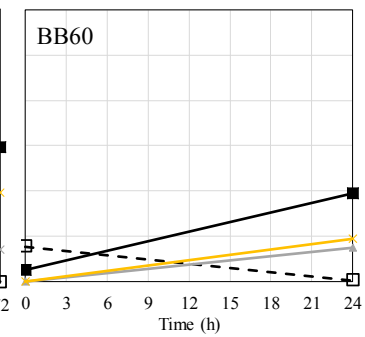

8505

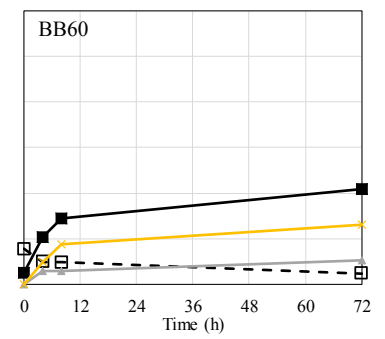

8520

Figure 3. Changes in the amount $\mathrm{CH}$ and $\mathrm{C} \hat{\mathrm{C}}$. The amounts of $\mathrm{C} \hat{\mathrm{C}}$ coming from $\mathrm{CH}$ carbonation and other hydrates carbonation are also illustrated in grey and yellow lines. 


\subsection{Difference in Calcium Carbonate}

Figure 4. shows XRD patterns for carbonated and non-carbonated samples. To compare the presence of $\mathrm{CH}$ and three polymorphs of $\mathrm{C} \hat{\mathrm{C}}$, only the range from $25^{\circ}$ to $35^{\circ}$ is shown in the figure. In general, $\mathrm{CH}$ peaks do not disappear after carbonation and their peak height is higher when samples are carbonated at $60 \% \mathrm{RH}$, which agrees with TGA results. In regard to $\mathrm{CC}$ calcite and vaterite peaks are observed in every pattern, but their proportion of peak height is different depending on relative humidity. At Vaterite peak height of $60 \% \mathrm{RH}$ (orange) is higher, whereas at calcite peak that of $85 \% \mathrm{RH}$ (grey) is higher. Aragonite can be found only in 5\% carbonation (N45_6005 and BB60_6005).
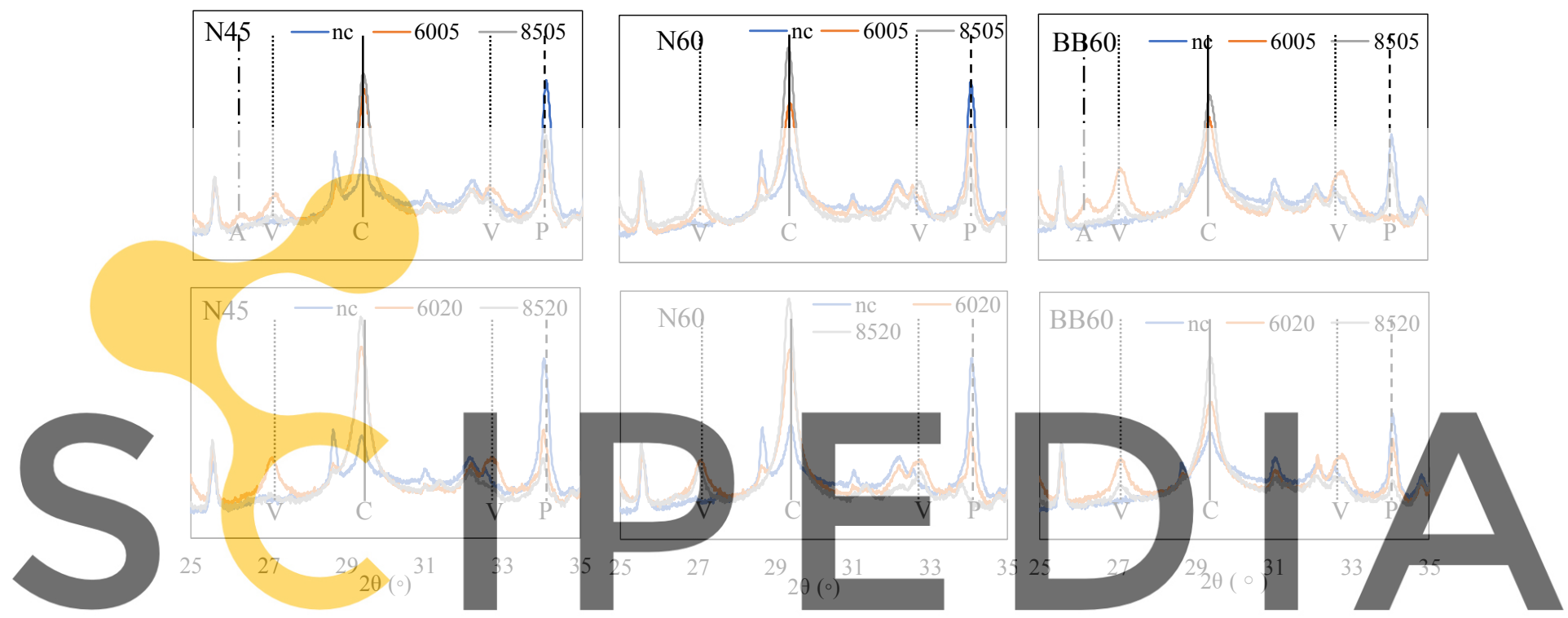

Figure 4. XRD patterns for carbonated $(6005,8505,6020$ and 8520) and non-carbonated (nc) samples. A, C, V Register for free at https//wwW.scipedia.com to download the version without the watermark

\subsection{Color Change During Phenolphthalein Test}

Table 1. and Figure 5. show the results of the phenolphthalein tests. Here, the color difference before and after phenolphthalein addition is determined based on CIE $\mathrm{L}^{*} \mathrm{a}^{*} \mathrm{~b} *$ color space, where $a^{*}$ coordinate indicates red (positive) or green (negative). The color of non-carbonated samples turns red immediately and $\Delta \mathrm{a}^{*}$ value reach around 50 whereas, color change of carbonated samples is slower and their $\Delta \mathrm{a}^{*}$ value is below that of non-carbonated. The results of carbonated samples also indicate that carbonation environment (both external humidity and $\mathrm{CO}_{2}$ concentration) affects the sensitivity to the indicator, that is to say, $\Delta \mathrm{a}^{*}$ value is smaller when relative humidity and $\mathrm{CO}_{2}$ concentration are higher. In addition, the effect of relative humidity is greater than that of $\mathrm{CO}_{2}$ concentration. 
Kiyofumi Nakada, Katsuhito Komiya, Hikaru Fumino, Yuhei Nishio, Manabu Kanematsu and Takafumi Noguchi

Table 1. Photographs of compacted samples 60 minutes after phenolphthalein indicator was dropped. Color difference index $\Delta \mathrm{a}^{*}$ (positive: redder and negative: greener) is also shown below each photograph.

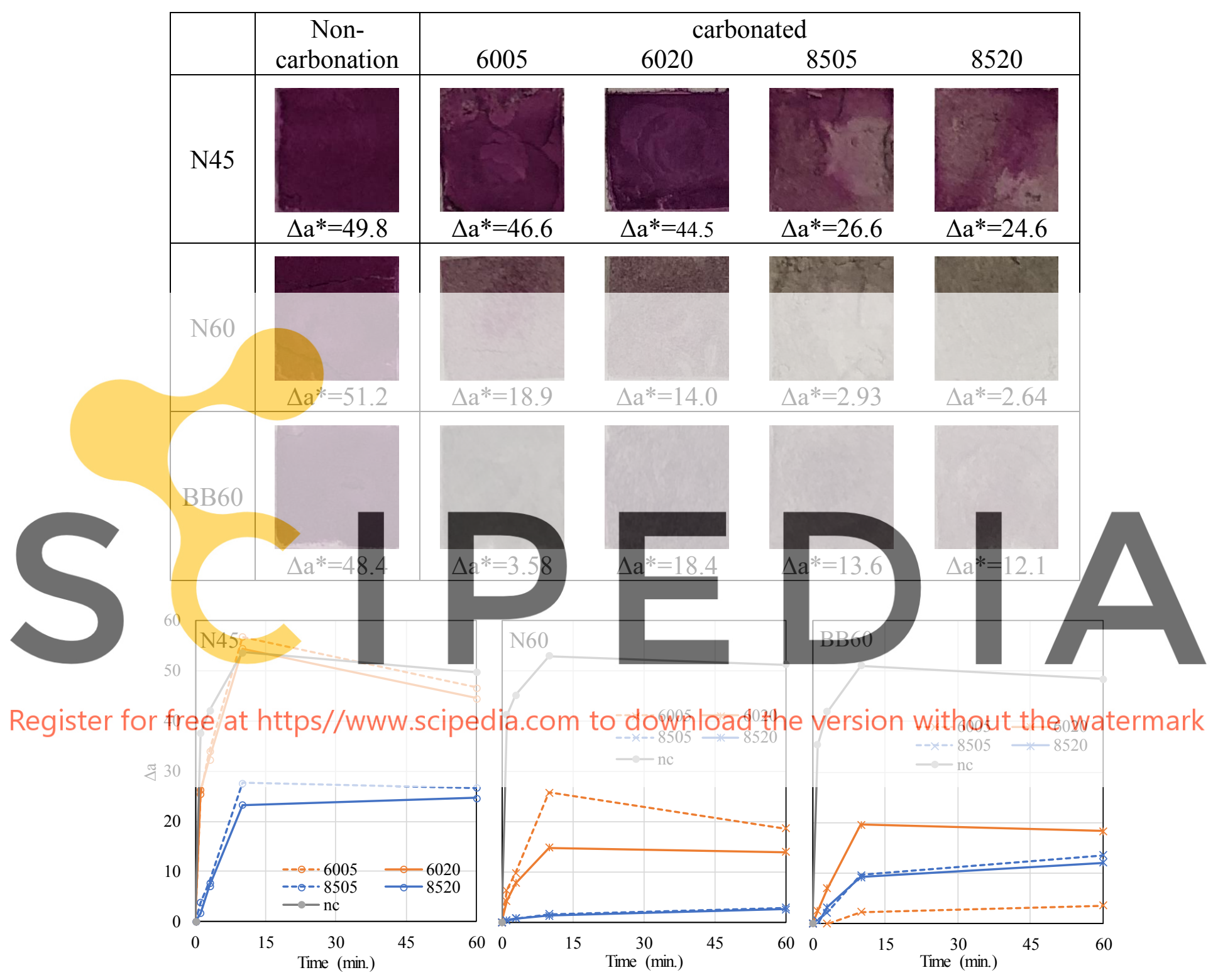

Figure 5. Changes in $\Delta \mathrm{a}^{*}$ after phenolphthalein indicator was dropped. Non-carbonated (nc), carbonated at $60 \% \mathrm{RH}$ and carbonated at $85 \% \mathrm{RH}$ are illustrated as grey, orange and blue lines respectively. 


\section{Discussions}

Based on the obtained results, carbonation behavior of cement hydrates and their impact on concrete properties are discussed. First of all, the results of weight increase (Figure 2.) do not agree with the increase in $\mathrm{C} \hat{\mathrm{C}}$ amount after carbonation (Figure 3.). In other words, TGA results indicate that less amount of $\mathrm{CO}_{2}$ is absorbed at $85 \% \mathrm{RH}$, whereas the weight increase is greater at $85 \% \mathrm{RH}$. According to natural carbonation tests (Galan et al., 2012), larger amount of water is released from CSH when it is carbonated at lower relative humidity (about $38 \% \mathrm{RH}$ and $58 \%$ are compared). Although the carbonation environment is different from that of the current study, this carbonation behavior of CSH can explain the reason for the disagreement in the figures 2 and 3. When the powder samples are carbonated at lower relative humidity, more $\mathrm{H}_{2} \mathrm{O}$ can be released from $\mathrm{CSH}$ due to drying and weight increase due to $\mathrm{CO}_{2}$ uptake is canceled.

Regarding to carbonation behavior of $\mathrm{CH}$ and other hydrates, the impact of relative humidity is clearly observed. As has been pointed out, $\mathrm{CH}$ carbonation is promoted at higher relative humidity $(85 \% \mathrm{RH})$ and less amount of $\mathrm{CH}$ remain uncarbonated. Compared to the results of phenolphthalein test, the amount of residual $\mathrm{CH}$ can be related to color change of phenolphthalein. On the other hand, other hydrates carbonation is promoted at lower relative humidity $(60 \% \mathrm{RH})$. As a result, at $60 \% \mathrm{RH}$, other hydrates carbonation proceeds without enough $\mathrm{CH}$ carbonation. Because other hydrates carbonation is more responsible for pore structure changes and carbonation shrinkage, changes in cement paste properties can occur without color change of phenolphthalein in such environments.

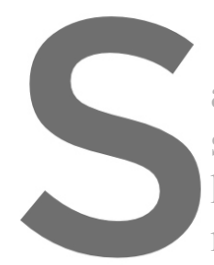

As mentioned in around surface of bu situation, carbonation hydrate carbonation main factor for CSH carbonation and decompositi
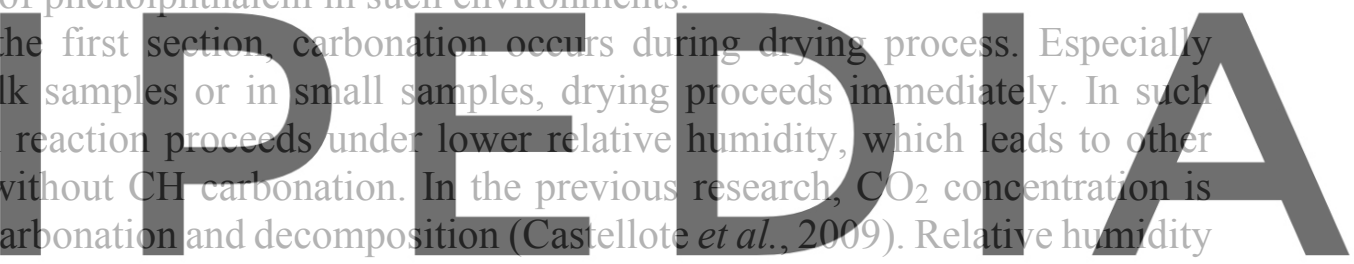

also affects CSH carbonation, and this factor should be taken into account when estimating

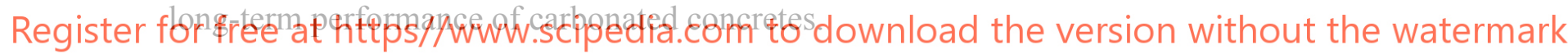

\section{Conclusions}

- Powdered cement pastes were carbonated in order to investigate the impact of external environment on carbonation behavior of $\mathrm{CH}$ and other hydrates.

- The results of weight increase do not agree with that of TGA tests. The disagreement can be related to the effect of relative humidity on stoichiometry coefficient of $\mathrm{H}_{2} \mathrm{O}$ $\mathrm{CSH}$ carbonation reaction.

- $\mathrm{CH}$ remain uncarbonated even after $\mathrm{CO}_{2}$ uptake apparently end and the amount of the residual $\mathrm{CH}$ affects the results of phenolphthalein test. External humidity strongly affects the carbonation behavior of both $\mathrm{CH}$ and other hydrates. The degree of $\mathrm{CH}$ carbonation is greater at higher humidity, while the degree of other hydrates carbonation is greater at lower humidity. The conflicting effect above can occur at surface of bulk concretes, and changes in its properties (especially coarsening of pore structure and cracking) can be induced without apparent carbonation detected by phenol phthalein test.

- Relative humidity, as well as $\mathrm{CO}_{2}$ concentration, strongly affects $\mathrm{CSH}$ carbonation, and 
this factor should be taken into account when estimating long-term performance of carbonated concretes.

\section{ORCID}

Kiyofumi Nakada: https://orcid.org/0000-0003-2744-1669

Katsuhito Komiya: https://orcid.org/0000-0001-8331-677X

Yuhei Nishio: https://orcid.org/0000-0002-9865-8606

Hikaru Fumino: https://orcid.org/0000-0001-9394-7372

Manabu Kanematsu: https://orcid.org/0000-0003-2473-0625

Takafumi Noguchi: https://orcid.org/0000-0001-6115-2292

\section{References}

Auroy, M. et al. (2015). 'Impact of carbonation on unsaturated water transport properties of cement-based materials', Cement and Concrete Research. Elsevier Ltd, 74, pp. 44-58. doi: 10.1016/j.cemconres.2015.04.002.

Borges, P. H. R. et al. (2010). 'Carbonation of CH and C-S-H in composite cement pastes containing high amounts of BFS', Cement and Concrete Research, 40(2), pp. 284-292. doi: 10.1016/j.cemconres.2009.10.020.

Chen, J. J., Thomas, J. J. and Jennings, H. M. (2006). 'Decalcification shrinkage of cement paste', Cement and Concrete Research, 36(5), pp. 801-809. doi: 10.1016/j.cemconres.2005.11.003.

Castellote, M. et al. (2009). 'Chemical changes and phase analysis of OPC pastes carbonated at different CO2 concentrations', Materials and Structures, 42(4), 515-525. doi: 10.1617/s11527-008-9399-1.

Galan, I., Andrade, C. and Castellote, M. (2012). 'Thermogravimetrical analysis for monitoring carbonation of cementitious materials Uptake of CO2 and deepening in C-S-H knowledge', J Therm Anal Calorim, 110, 309319. doi: 10.1007/s10973-012-2466-4

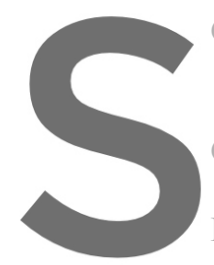

Galan, I., Andrade, C. and Castellote, M. (2013). "Natural and accelerated at different relative 10.1016/j.cemconres.2018

ssessmen Concrete Research. El.ser

Houst, Y. F. and Wittman

O2 through hydrated cement pas
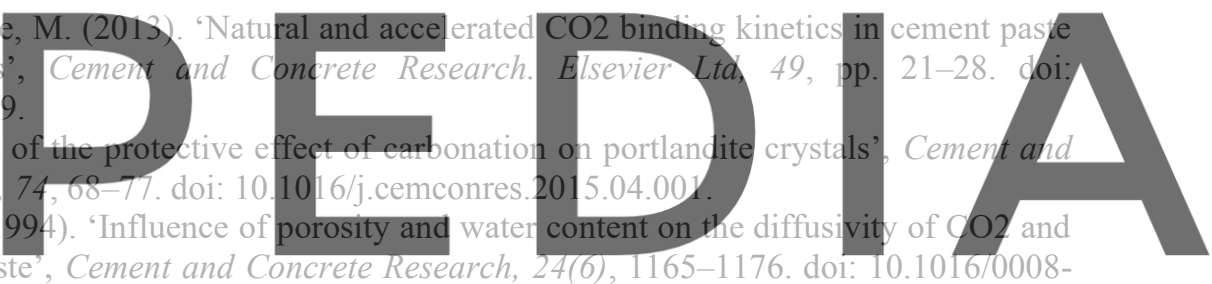
8846(94)90040-X

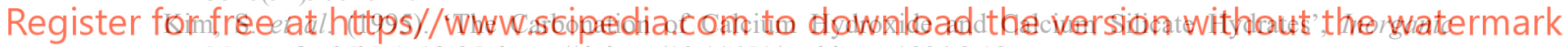
Materials, 2(254), 18-25. https://doi.org/10.11451/mukimate1994.2.18

López-Arce, P. et al. (2011). 'Influence of relative humidity on the carbonation of calcium hydroxide nanoparticles and the formation of calcium carbonate polymorphs', Powder Technology. Elsevier B.V., 205(1-3), 263-269. doi: 10.1016/j.powtec.2010.09.026.

Morandeau, A., Thierry, M. and Dangla, P. (2014). 'Investigation of the carbonation mechanism of CH and C-S$\mathrm{H}$ in terms of kinetics, microstructure changes and moisture properties', Cement and Concrete Research. Elsevier Ltd, 56, 153-170. doi: 10.1016/j.cemconres.2013.11.015. 